\title{
An introduction to "A symposium with Professor Roger Brownsword: super-stewardship in the context of public health"
}

\author{
MARK L FLEAR* \\ Queen's University Belfast
}

\begin{abstract}
Stewardship is mentioned in Professor Roger Brownsword's work on new and innovative technologies as "a significant item of unfinished business". ${ }^{1}$ In recent years, stewardship has arisen in other contexts, most notably the environment and public health. ${ }^{2}$ The latter is the immediate context for consideration of stewardship and the development of "superstewardship" in this special issue. The articles assembled were originally presented in the symposium with Brownsword that was held on 14 November 2009 at the School of Law, University of Sheffield. The articles also engage with the 2007 report of the Nuffield Council on Bioethics, Public Health: Ethical issues (Nuffield), ${ }^{3}$ which Brownsword coauthored, and occasionally the World Health Organisation's (WHO) version of stewardship put forward in its World Health Report 2000. ${ }^{4}$ In the policy world, stewardship is of ongoing relevance given that Nuffield has recently been adopted by the National Institute for Health and Clinical Excellence (NICE), ${ }^{5}$ the body that gives guidance and recommendations to the National Health Service on new and existing medicines, treatments and procedures.

More detailed and alternative understandings of stewardship and super-stewardship are provided in the articles, all of them in different ways attesting to the continued salience of the terms. Still, it is useful here to indicate stewardship's general contours, and I do so by reference to the summary of Nuffield by three of its authors - Baldwin, Brownsword and Schmidt - as follows:
\end{abstract}

liberal states have responsibilities to look after important needs of people both individually and collectively. Therefore, states are stewards both to individual

* Lecturer in Law, School of Law, Queen's University Belfast (m.flear@qub.ac.uk). The support of the British Academy (SG-48186 EU Governance of AIDS, Cancer and Obesity: Governmentality, Citizenship and Polity), the Economic and Social Research Council (PI: RES-451-26-0764 European Law and New Health Technologies) and UACES (PI: A Symposium with Professor Roger Brownsword: Super-stewardship in the Context of Public Health) are acknowledged with gratitude.

1 R Brownsword, "So what does the world need now? Reflections on regulating technologies" in R Brownsword and K Yeung (eds), Regulating Technologies: Legal futures, regulatory frames and technological fixes (Oxford: Hart 2008), p. 47.

2 See further: J Coggon, "What help is a steward? Stewardship, political theory, and public health law and ethics" and S Holm, 'From steward to Stuart: some problems in deciding for others', both in this special issue.

3 Nuffield Council on Bioethics, Public Health: Ethical issues (London: Nuffield Council on Bioethics 2007).

4 WHO, World Health Report 2000 (Geneva: WHO 2000).

5 See A Killoran and P White, "NICE public health guidance" (2010) 32(1) Journal of Public Health 136. NICE: www.nice.org.uk/aboutnice/ (last accessed 5 September 2011). 
people, taking account of different needs arising from factors such as age, gender, ethnic background or socio-economic status, and to the population as a whole ... [T] he notion of stewardship gives expression to the obligation on states to seek to provide conditions that allow people to be healthy, focussing attention, in particular, on reducing health inequalities. ${ }^{6}$

In Nuffield, stewardship is posited on states. Moreover, as elaborated in the collection, Nuffield provides a rights-based approach to incorporate a precautionary way of thinking in public health contexts aimed specifically at the population level. Linking to "superstewardship", Nuffield also notes that it is "also reasonable" to apply stewardship at a "much bigher level". 7 The obligation of countries to notify others of a serious infectious disease outbreak in accordance with WHO procedures is used as an entry point for consideration of international and supranational responsibilities in the context of public health. The salience on that context is highlighted by inter alia recent pandemic alerts - and the ongoing problem of HIV/AIDS.

A single special issue cannot cover the whole of this emerging field of interest. One way of viewing the collection and its contribution is by highlighting the core contribution of each article. In his keynote article, Brownsword refines and extends his earlier thoughts on the scope and function of stewardship as it is linked to broader concerns on the idea of a "regulatory environment" and "regulatory prudence". Brownsword's conception of stewardship contrasts with Nuffield in that the state is not merely fulfilling responsibilities to its citizens, but is transformed into an (aspirant) moral community striving to flourish and develop. ${ }^{8}$ This line of thought is extended such that stewardship is conceived as the ongoing responsibilities in relation to the routine running of community life and superstewardship responsibilities relate to the preservation of the staging or infrastructure for moral community. The article enriches and reinforces the foundations of stewardship and super-stewardship and opens up space for reflection on the meaning and scope of "responsible regulation".

Complementary criticisms of stewardship and super-stewardship are put forward by Coggon and Holm. For Coggon, stewardship does not provide a basis for robust analysis in public health law and ethics. Rather, stewardship adds little as a label for unsubstantiated normative conclusions or issues of good governance better addressed directly in theory. Coggon argues that stewardship is not a sound basis for policy or critical scholarship, especially since it might obscure rather than expose important normative argument. Still, in a way that resonates with Flear's article (see below), Coggon acknowledges stewardship's possible benefits as a public bioethical discourse.

Holm explores stewardship and super-stewardship from a critical philosophical point of view in order to tease out their internal coherence, justification, difference from paternalism, and value in guiding action. Overall, it is argued that Nuffield cannot be differentiated from paternalism and that while Brownsword's conception of stewardship does contain a justification through reference to the "aspirant moral community", Nuffield provides no clear justification for stewardship. Holm suggests there is an even weaker justification for super-stewardship. The upshot, then, is that both Holm and Coggon query the wisdom and use of stewardship and super-stewardship.

6 T Baldwin, R Brownsword and H Schmidt, "Stewardship, paternalism and public health: further thoughts" (2009) 2(1) Public Health Ethics 113, pp. 115-16.

7 Nuffield Council, Public Health, n. 3 above, p. 68 (emphasis added).

8 Cf. R Brownsword, Rights, Regulation and the Technological Revolution (Oxford: OUP 2008), p. 115. 
The articles by Hervey, Murphy and Flear apply stewardship and super-stewardship as tools to highlight and address public health problems and governance in international and supranational settings. Hervey argues that, with some adjustments, stewardship is as applicable to the European Union (EU) as super-stewardship. By drawing on insights from law and streams of European integration theory in particular, Hervey convincingly dismisses arguments against the application of super-stewardship to the EU as a catchy and evocative description of its responsibilities in law and policymaking. She also provides examples of how EU super-stewardship can be discerned and assessed.

Murphy uses Nuffield as a reference point to launch consideration and promote critique of the roles of non-governmental organisations (NGOs) in public health, and especially in relation to HIV/AIDS - and indeed to propose a revised Nuffield that engages with the phenomenon she terms "public health sans frontières". Such a report would include attention to and discussion around three particular points: consideration of the relationship between human rights and humanitarianism in the public health arena; the nature, scope and form of the commitment of global human rights NGOs to public health issues; and the particular challenges of buman rights triage. In extending super-stewardship to NGOs, Murphy highlights a new space in which activists and citizens in general can demand and contest action in public health by NGOs. She stresses that this sort of biopolitics should take place against the background of "global health security" as the context that produces challenges and opportunities for human rights NGOs who work in the field of public health.

Recognising the importance of attuning stewardship to the specifics of the EU's sui generis supranational legal and political order, Flear focuses on its function as public bioethics and reformulates it as "supra-stewardship". Using pandemic planning as a case study, he proposes supra-stewardship as a tool that leverages support from human rights and bioethics and which can be used to facilitate citizen participation in governance around the focal points of framing, distribution, vulnerability and learning. This participation could query the limits of EU responsibility and the production of governance distortions and failures. Flear suggests this could bring out the normative in the technical and contribute important supplementary knowledge to the assemblage brought together, structured by preparedness, and used to govern pandemics.

As Brownsword points out in the conclusion to his article, stewardship and the practical and theoretical work around it are destined to remain items of unfinished business as governance struggles to keep up and connect with its fast-moving technological and societal targets. While this special issue is testament to that observation, it also helps to foster much needed scholarly discussion and critique - and to ensure this field is not unwittingly formed and deployed by and as a legitimating support for governance, but rather opened up, elaborated and contested. The articles provide innovative insights and food for thought on the conception and legal-political practice and potential of stewardship and superstewardship in national, supranational and international settings. 
